\title{
关于銅鉄冶金科学方面的成獸与任务
}

\author{
Л. M. 崔辽夫 \\ （中国科学院鹤問）
}

一蝀 铁

冾金業是国民緅济的基㖄。

最近 $45-50$ 年內生鉄的高大大地提的了。例如，以 1905 年世界比生鉄产量为 $5,213.3$ 万阶, 則 1935 年为 6,149.9 万吨，1940 年为 9,120 \%万吨，1950 年为 $10,738.4$ 万 吨。目前已大大超过最厉的这个数字了。我們举像比利似这样一个不大的国家为例, 它 在 1935 年生产生鉄 131.1 万吨，1940 年生产 222 万吨，1950 年生产 369.7 万吨。美国

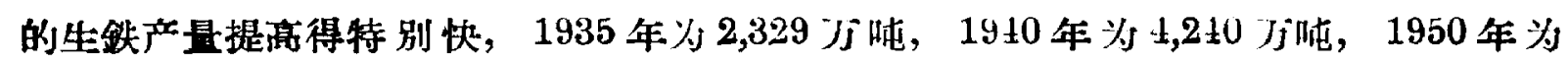
$5,935.4$ 万吨。究竟是依靠什么能够这样快地提淿生鉄 ${ }^{\prime}$ 量呢?

（1）改建旧高啮，即从加大有效容积井同时㙁大鼓風机能力着手进行改建;

（2）建造更巨型的亭㠊;

(3) 强化消爈过程;

（4）装料、处理熔煤产物等繁重工作完全自动化与机械化。每㫫夜里 产 1,500 吨 生鉄的現代化高堵需要約 4,000 吨原料, 而每班最多只要 $5-6$ 个人参加裝料工作。

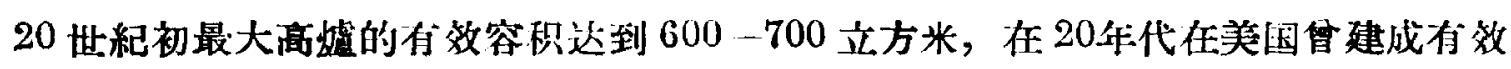
容积为 900-1,000 立方米的高煴, 1948 作在苏联售建筑了有效容积为 1,300 立方米的最 大的婎子。現在，在苏联正在建筑有效容积为 1,500 立方米的㠊子。

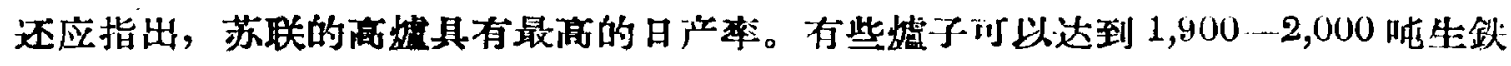
的日产量。利用较完善的原料准备法、改善嘘子的操作方法及梁用一系列的帮助强化漓 㠊过程的措施, 即可达到这样消的生产率。

强化高烧过程的問题是很有价值的。因此，世界．．的許多国家的許多治全工作者都 研究着这个問題。

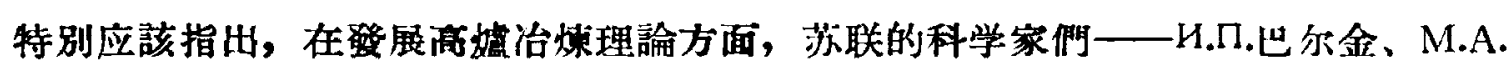

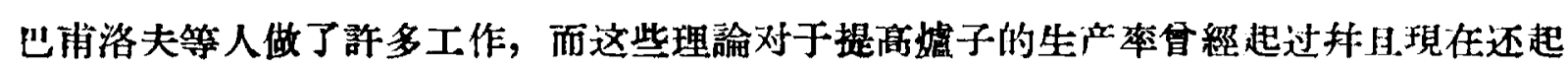
着重大的作用。現在，無論在苏联或者在外国，在寻找及推广更有效的调踖操作方法 上, 在研究許多理論問題.上, 都进行着广泛的科学研究工作。

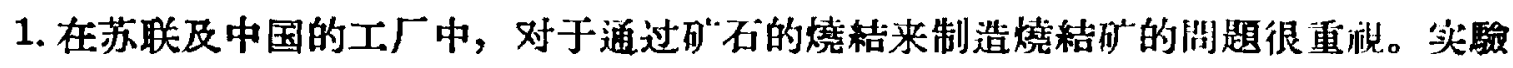

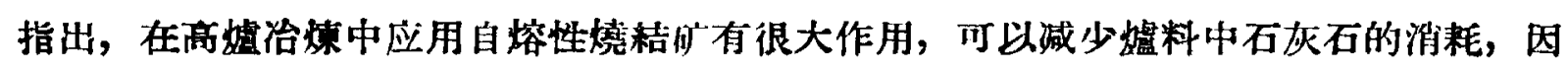

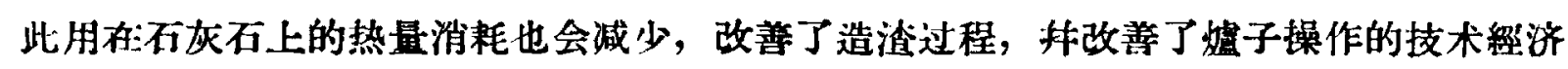

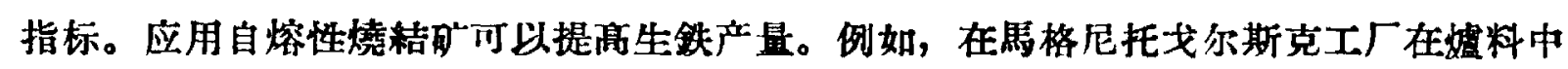




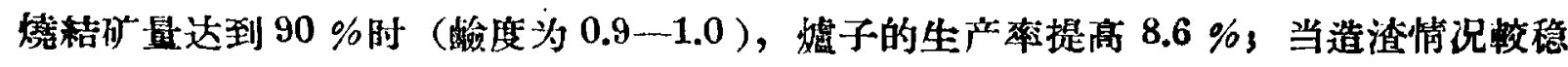
定、惯子順行时减少燃料的消耗 $6.4 \%$ 。进一步改善易还原自熔性燒䊅矿的制造 也是冶 金科学家及生产工。作者們重大科学砰究任务之一。

要获得好的自熔性燒結旷“究竟需要那些基本的条件呢? 首先石灰石姴粉碎得很紬， 細到 0-3 毫米, 这样可以促进燒結料更好地造矿球, 科提信燒結机的生产率。很显然, 为达到此目的需要研究合理的燒結工艺过程。

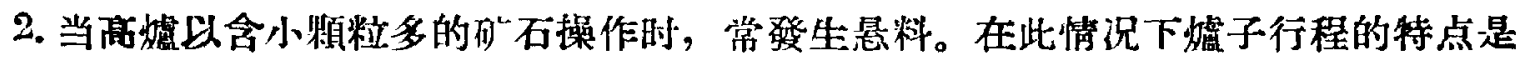
崩料, 㛭子的生产率降低。应該找出在此情况下烤子比較順行的方法, 即提高生产率的

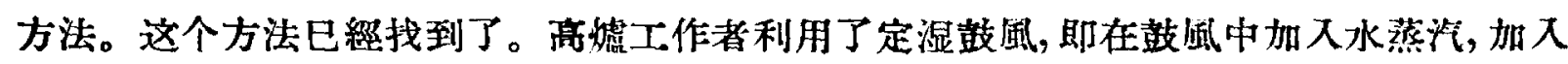

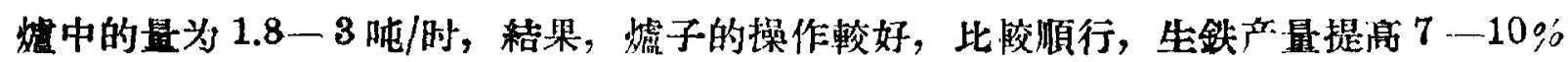
以.上。

然而, 在这方面还没有詳尽的理論資料。可能是風管附近氧化帶的体积㘿加了, 此

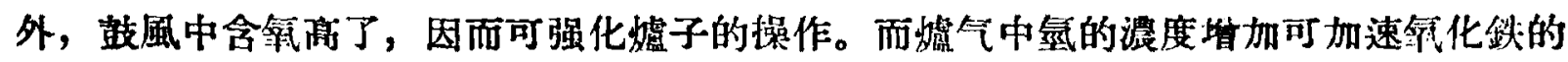
还原反应。

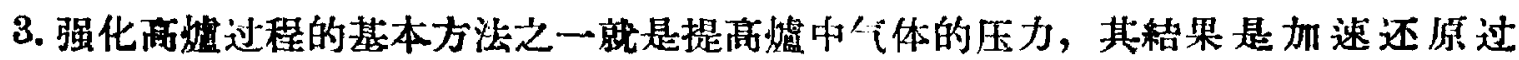
程。此时, 矿石的謏鹿吹出量减少, 焦炭的消耗最降低了。

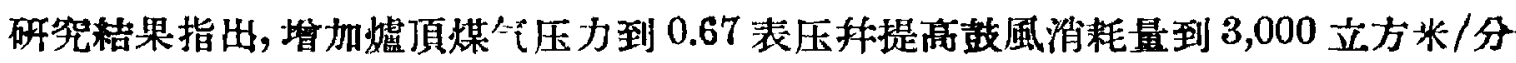

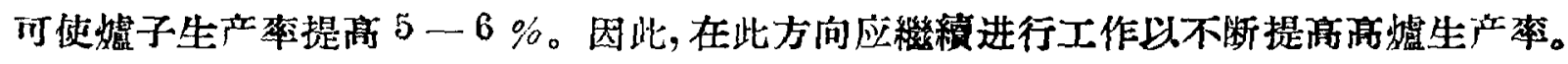

这里过程的理諭也倘末研究出，故应在此方向繼續工作。

然而，通过实驗室及工厂的研究已确定，随着气体压力的增滆生鉄中含碃量降低。

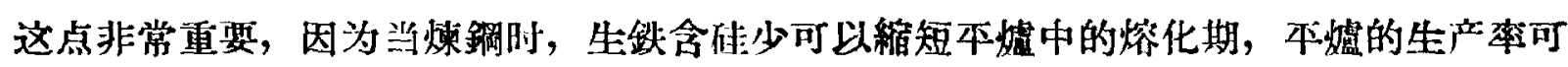

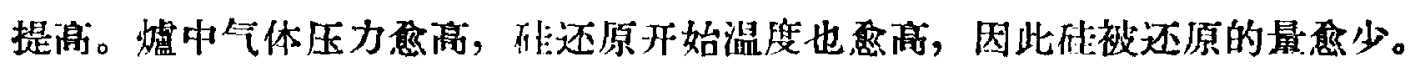

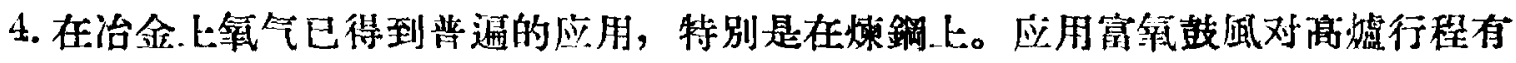

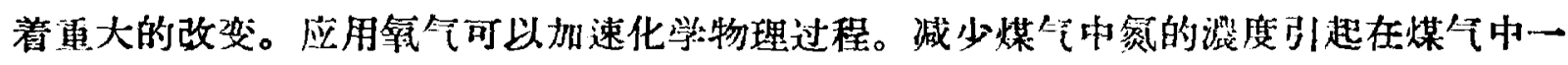

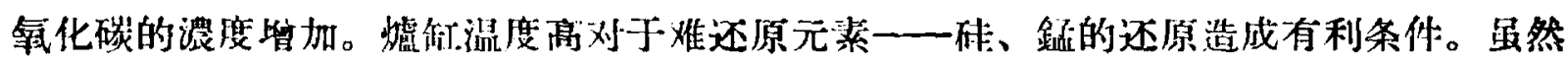

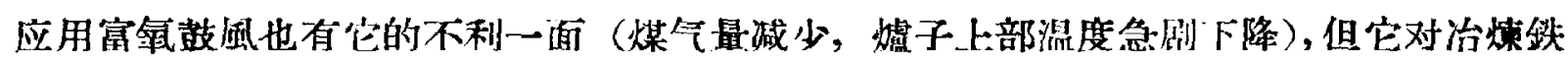
合金（鉟鉄、硅鉄等）特別有利。显然，有关治栔普通生鉄的工作还需进行一些研究， 因为利用氧气可以大大强化暂子的操作, 故在此方向应进行工作。

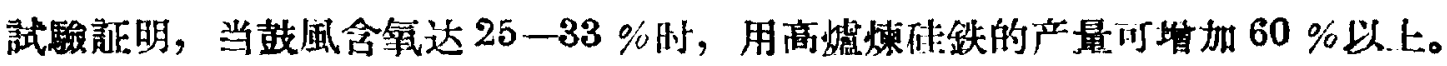

5. 目前在国外，特別是在美国，对于矿石造地問题，特別是用碎矿石及精们造成矿” 球的問題非常重視。如集造成自聺性的球持加入燃料做还原刹, 則可得良好效果。將来

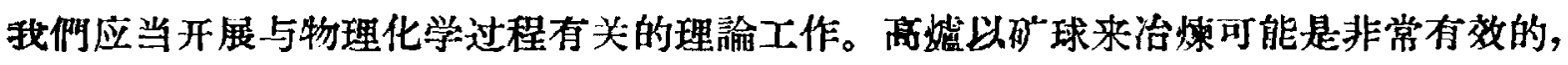
因为矿石、熔剂及燃料彼此紧密接触。此外，还可以指出一系列的可以强化高堵工作似

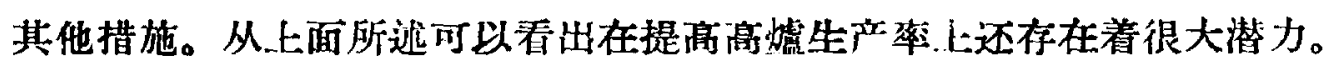

6. 蟅过程的研品工作早就进行了。在这方面已有許多工作在学术上及实际上有着 宝貴的效果。現在都在那些方向进行工作呢?

現在，在苏联进行着下列工作:

（1）改进自熔性燒結矿”制造工艺过程; 


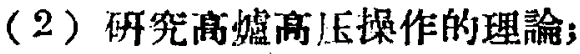

(3) 还原过程动力学;

(4) 亿体动力学仅热交換过程等。

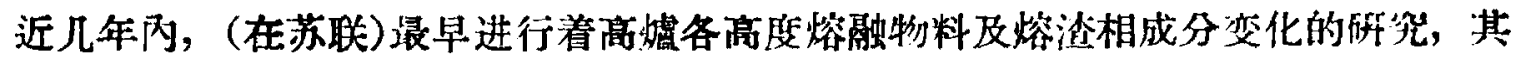

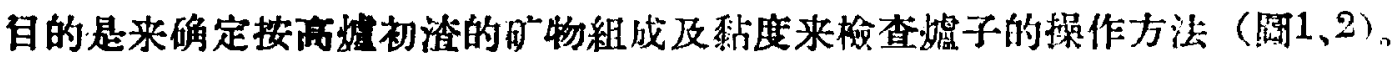

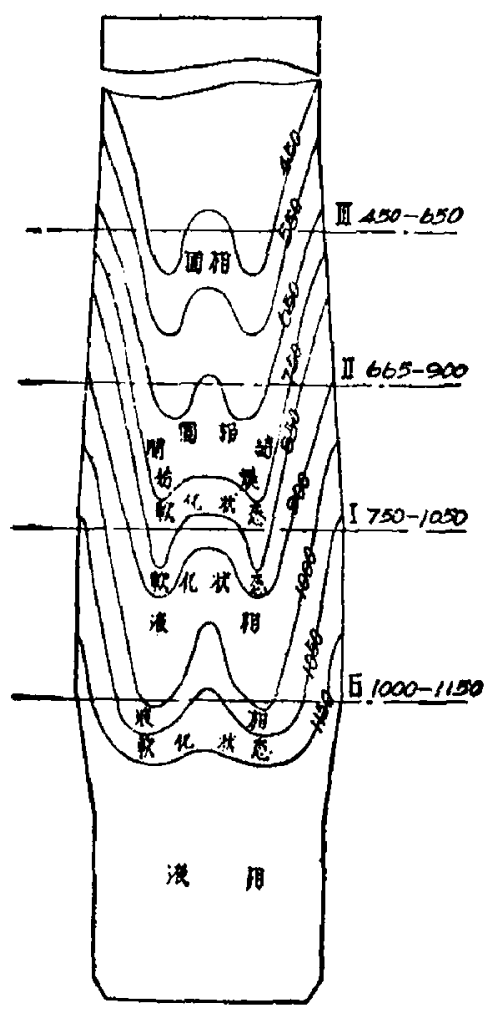

1

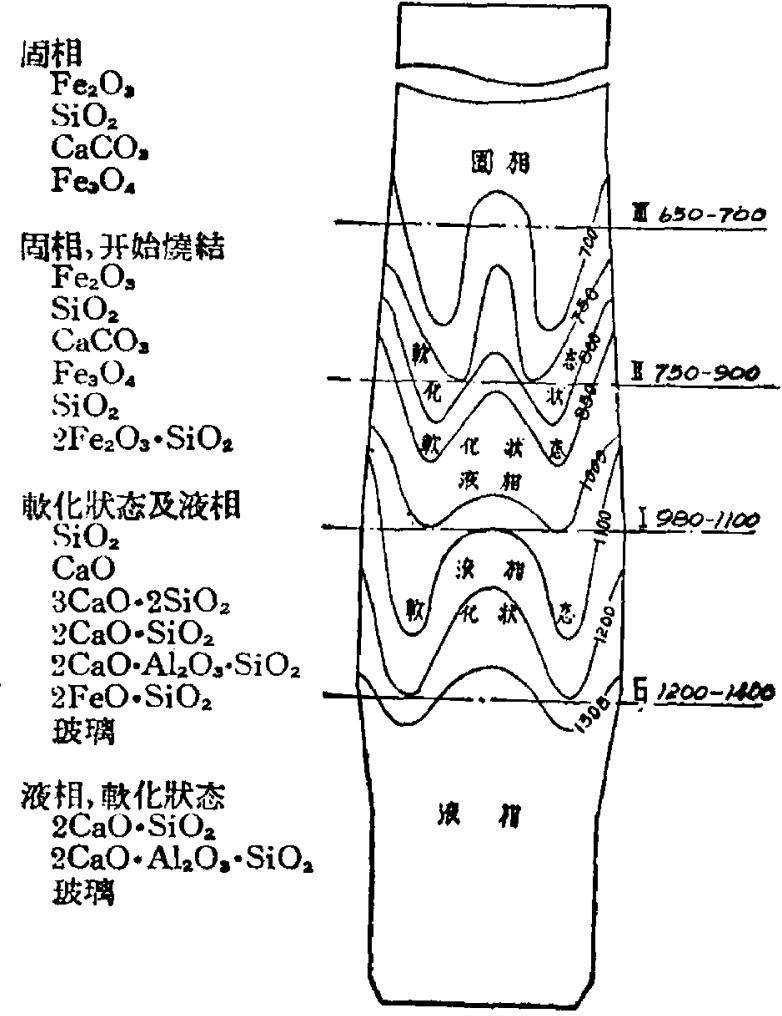

䦎相

$\mathrm{Mn}_{2} \mathrm{O}_{3}$

$\mathrm{Mng}_{\mathrm{s}}$

$\mathrm{SiO}_{2}$

$\mathrm{CaCO}$,

软化状念及湾相

$3 \mathrm{CaO} \cdot \mathrm{SiO}_{2}$

$2 \mathrm{CaO} \cdot \mathrm{SiO}_{2}$

$3 \mathrm{CaO} \cdot 2 \mathrm{SiO}_{2}$

$\mathrm{MnO}$

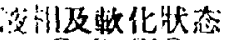

$2 \mathrm{CaO} \cdot \mathrm{SiO}_{2}$ *

$2 \mathrm{MnO} \cdot \mathrm{SiO}_{2}$

$\mathrm{MnO}$

$3 \mathrm{CaO} \cdot 2 \mathrm{SiO}_{2}$

$2 \mathrm{CaO} \cdot \mathrm{Al}_{2} \mathrm{O}_{3} \cdot \mathrm{SiO}_{2}$

$2 \mathrm{CaO} \cdot \mathrm{SiO}_{2}$

除去福嘘过程外，岩相学的研究还有什么意义呢?

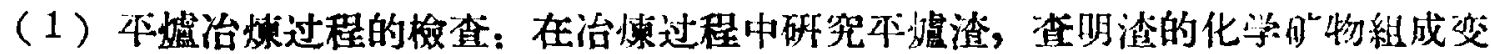
化与熔樏期閒关系的規律。

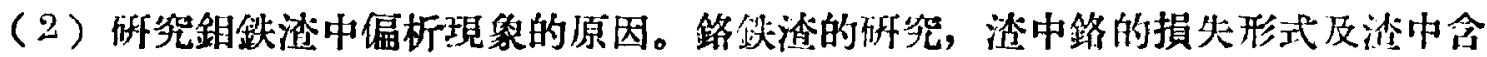
鉻不均匀現敖的产生原因等的研究。

(3) 用岩相学呼究可以确定钢在什么矿物相中存在，舟指出啝的最合适研物組成 以提语在化学法精熑时釷的抽出率。这种研究还可以找仙在生产䤼等时的较合适的唀成 分。

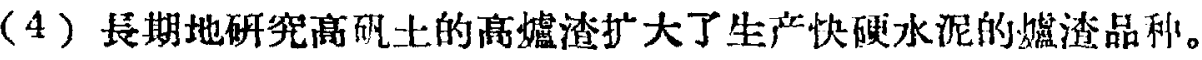

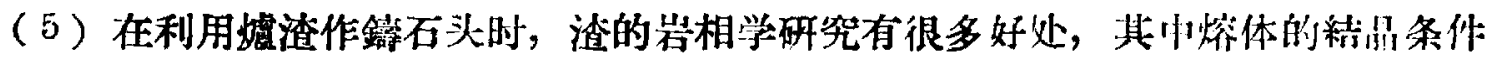
及其他因素有很大意义。

在等相研究中的問題，行很多大問題还未研究过，其中包括在各利冶金过程中渣的

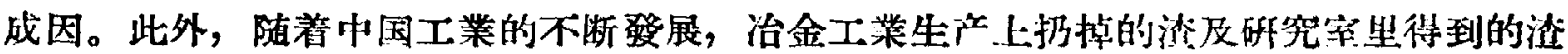
的数量和种类日登增多，这些渣也將会得到卖际应朋，如做康价的垏筑枋料。因此渣的 岩相学有被广閵的前涂。 


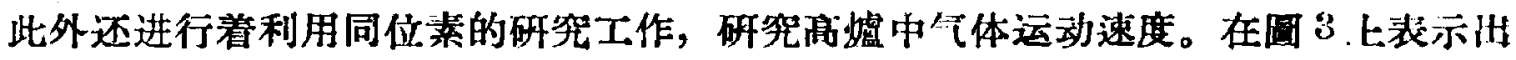
測定高嘘边緣处气体运动的国形。在此会应用了放 射性的氢，将氢从詝藏器逘入曥征中。

实驗測出, 如 $\frac{l}{H}=3(l$ 度，H一㠊子有效度度)，則櫖身中心体运动速度 与其下゙部造渣区气体运动速度不同。會得出，如增 加焦料，就会引起气体在爐子各消度的速度都增 加。增加鼓風的量, 就会引起煤气速度増高, 特别 是在造渣区的速度, 此外在嘘身中的速度算滈也很 显著。改变裝料系統对煤气速度也有影响。

研究絈果指出，在造渣区一体的速度为 30.6 61.3 米/秒，在㠊身为 22.4-28.3 米/秒。这就指出在 液态及牛液态物料区爐料的透气性羑。这类研究的 作用如何? 它可以給出这些气体在料柱的某一体积 內起作用的估計，推拟定利用气体的热能和化学能 的方法。

此外，对生鉄鍶外脫硫的問題也十分重視。研

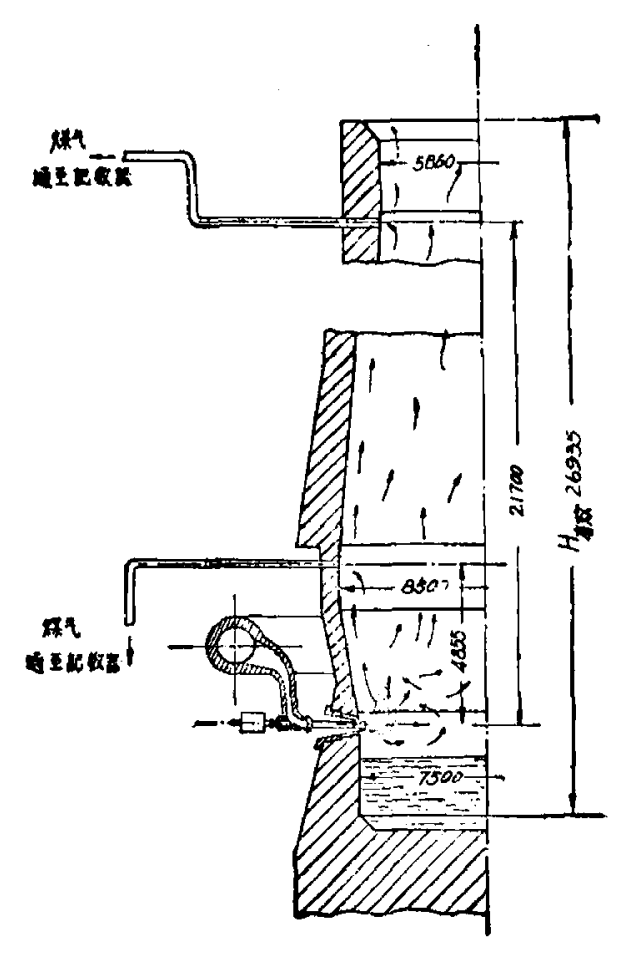

10in 3

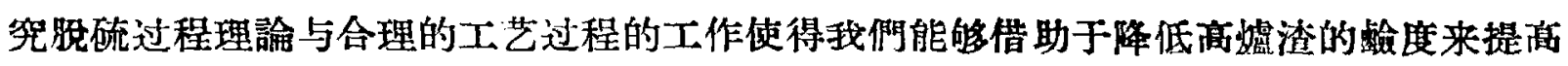

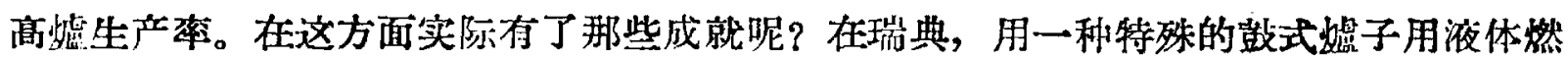
料燃燒加热进行脱硫, 很成功。在加热爐中倒入 $5-10$ 吨生鉄, 加上石灰与碎焦的混 合物，然后將堵子旋轉数分鐘。在此种操作以后，生銠中含硫降低到 60-70\%。在苏

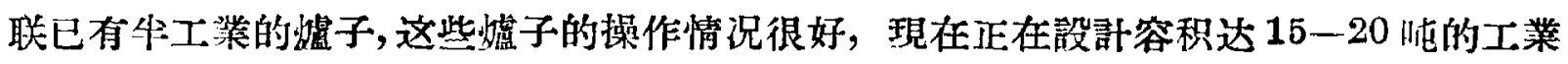
嘘。

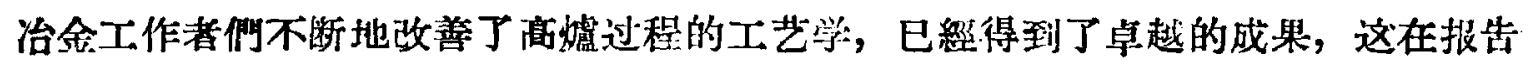
的一开始跳誂到了。

在开展进一步地研究滈復过程的工作中，中国的冶金工作者已提出了迫切的問題。 这些問題的解决将会以新的监料大大地丰富治金科学的內容。

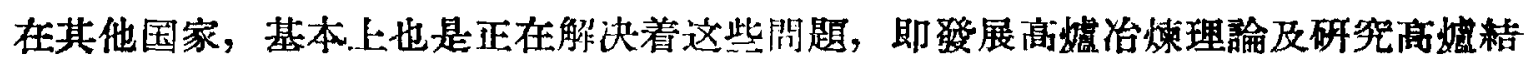
構及自动化設备等問題。

还应該指出, 現在, 在苏联首先研究着强化矿石燒結过程的方法, 即采取先將燒粘

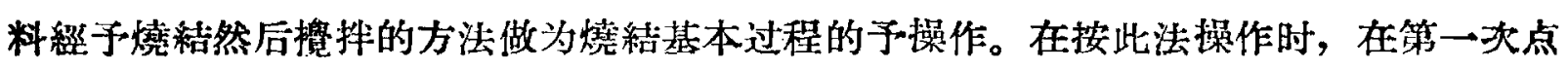

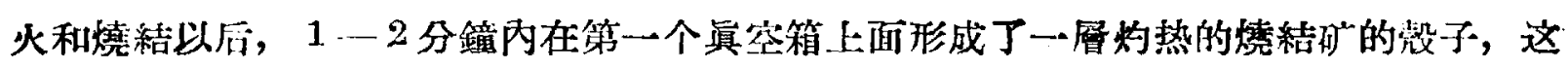
居壳在以后被混可器打碎，与第二个真空箱上的料混匀，鋪本，再以晋通点火煰点火。

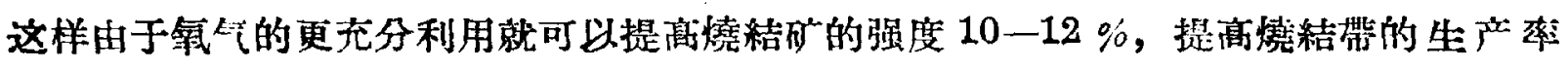
10.-15\%。

（6）电亮嘘，在某些情况下需要制造特种优筫生鉄，在电力較便目的地方，常朵用

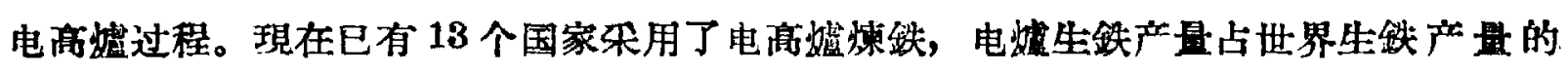
$0.5 \%$ ，即每年75万吨。 


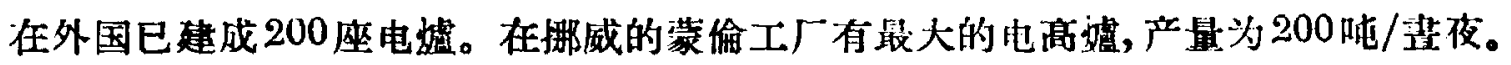

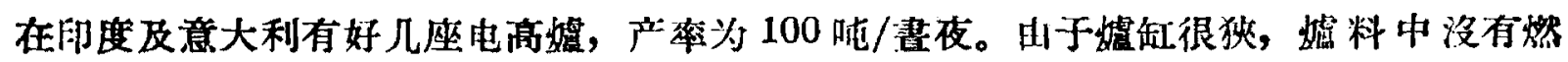

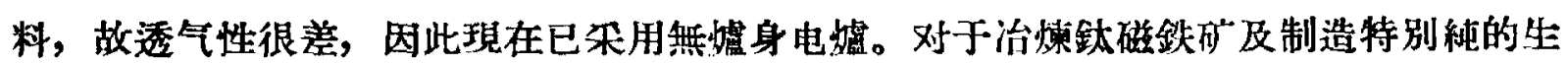

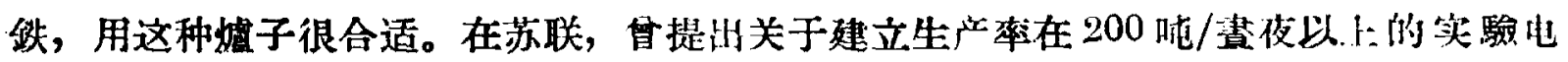

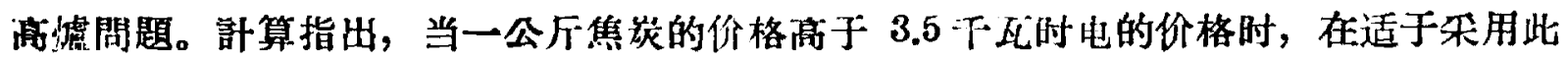

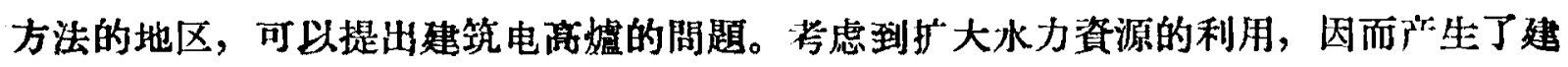

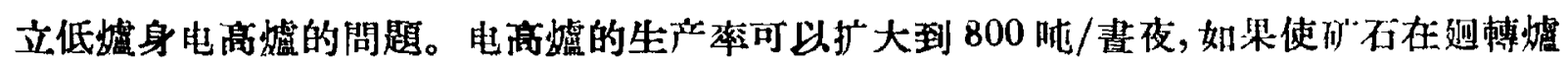

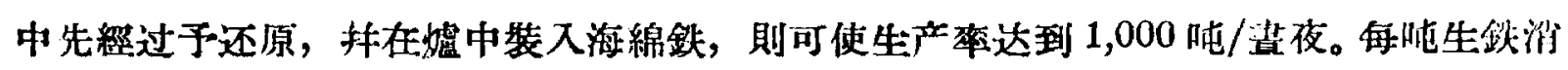
耗的电能为 2,300-3,000 千丽时, 消耗的焦炭为 380-405 公斤。

\section{二 冶金焦的制造}

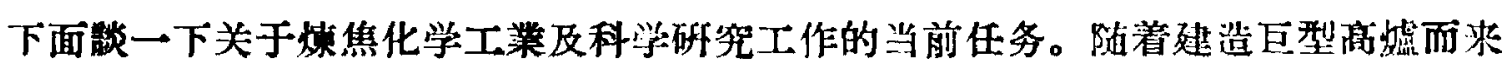
的是必須提高熑焦烧生产率及焦炭質量。为了进一步改良焦炭質量及圹大煉焦原料基地 的新任务, 在煤炭化学及物理化学方面的科学知識还是不足的。因此, 必须深入研究煤

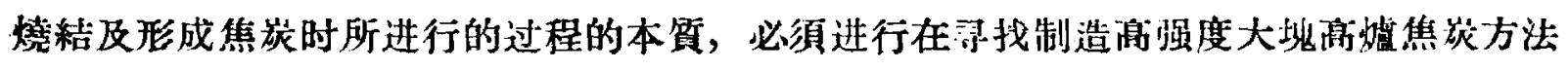
方面的工作。还必須研究結焦条件, 首先是加热速度对焦炭最終强度指标改焦炭坮度的 影响。炭化室加热問題具有很大意义。在炭化寀的不同長度与禹度加热忿均与, 焦炭筫 量盆调。选煤工艺过程对焦炭复量有很大影响。选煤工少过程应加以改善, 因为降低煤 中灰分及硫的含量在熯鉄上有巨大意义。

在吃上这些方向上，現在在䓇联及外国都进行着大量工作。

至于到現在为止在科学研究方面完成了那些工作呢? 叮以很简單地愦。政究了煤炭 加热时-所进行的过程的机構, 以及煤在熑焦混合料中的相互作用, 确定出固态残洫許多

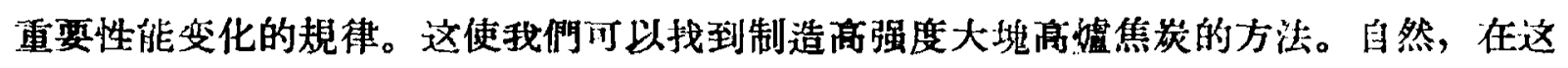

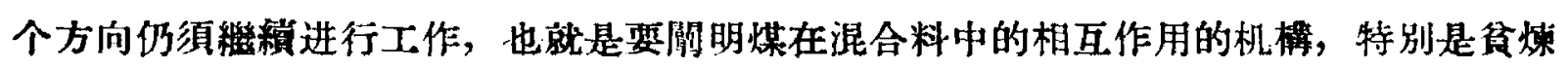
焦煤在混合料中的相互作用的机構。

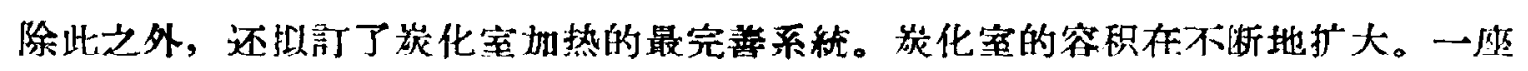

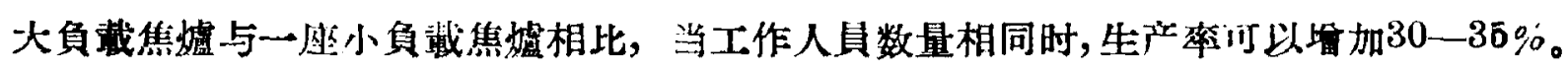
在国外 $87.3 \%$ 的焦嘘是用炭化室賞度为 $440-525$ 毫米的。

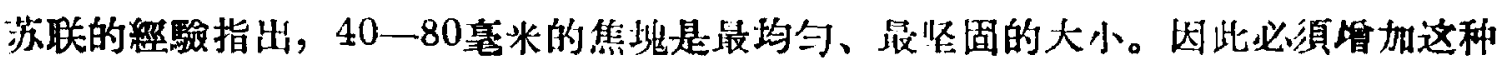
大小的焦塊含量。 80 毫米以上的焦兟就不坚固了（有裂䋖、生焦）。琴在有一利意見，

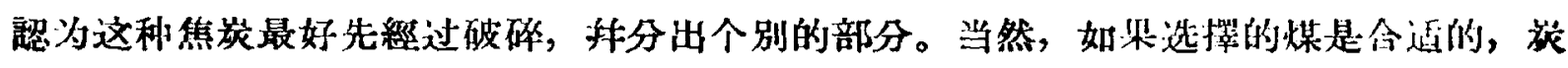
化室的加热是均匀的, 則大洗焦炭不需要經过破碎而仍有足的的强度。

\section{三低媞身高虫}

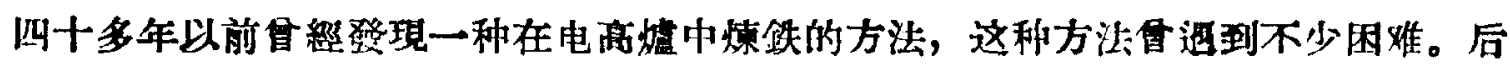

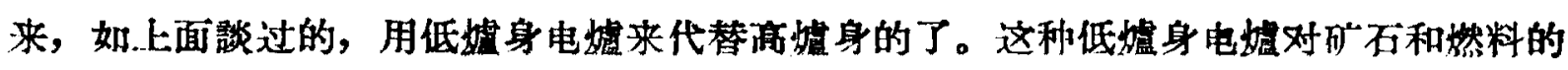

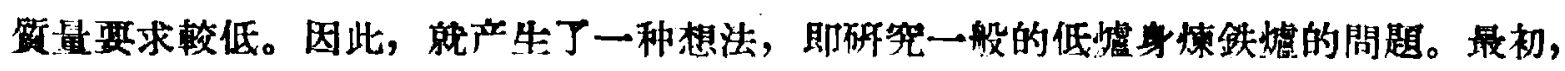

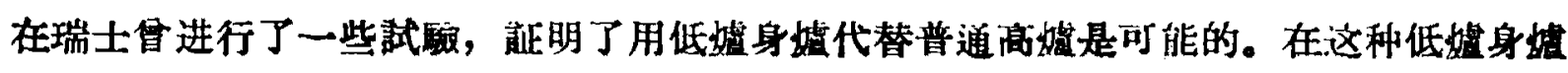


中甚至可以用干褐煤做燃料。当然, 它的消耗量是非常大的, 当鼓風中加入大量氯时, 其消耗約为 $300 \%$ 。現在在欧洲已有許多低嘘身㫮。只要举出下列事实就足以踪明，在 德意志民主共和国建成了11座低嘘身䞍，其中有10座是在靠近馬格德堡附近的新建的工 厂中，一座是在秋林吉亞的馬克斯休特老厂中。奥地利、比利时、西德也都有这种䞍 子。大部分都是方形截面的嘘子，例如德国的嘘子墻缸尺寸为：長边 6 米、短边 1.8 米

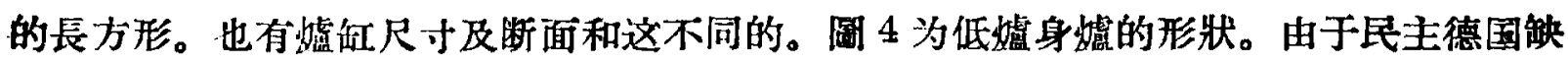

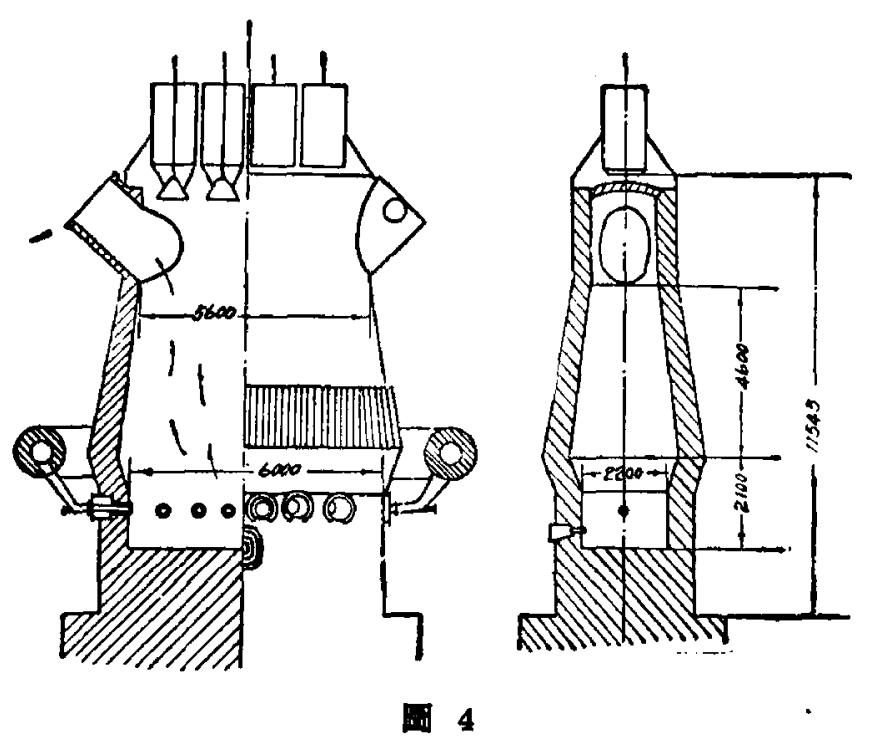
之鎬造用生鉄，而有含礁實的，缺 之治金焦炭，因此不得不建立低婲身 譃。矿石的質量很低, 含鉄仅为20$23 \%$ 。没有进行选矿。用的然料为褐 煤焦炭，是用褐煤团塊的方法制出 的, 然后將所得到的团塊用特殊的焦 嘘結焦。在民主德国鍄造生鉄的生产 問題很快地就得到解决了。在1951年

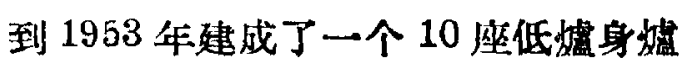
的工厂。堵子的尺寸是: 全滈 11 米, 㠊畋断面 $6 \times 1.8$ 及 $7 \times 1.5$ 米。有效调 度或熔融料柱语为 $4.8-6.0$ 米。料是 用叫个料鏡进行的。

容积 90 立方米的低身高嘘当加

入 25-30\% 的度鋼时，每書夜可炴 60-70 忳生鉄。

如果把低身爐的操作指标与一般高烧相比, 則它的所有各指标都较差, 因为它所煉

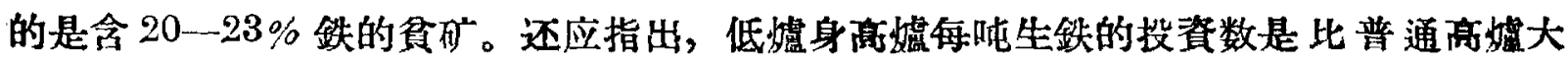

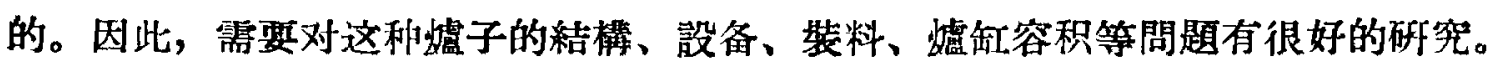

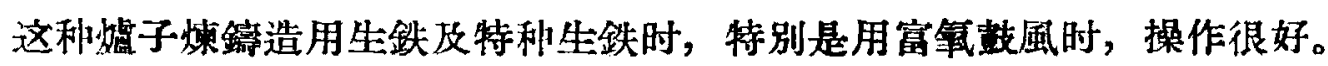

在富有适于制造平焦或瓦斯焦的許多非治金燃料地区可以建立小規模的低堵身嘘，

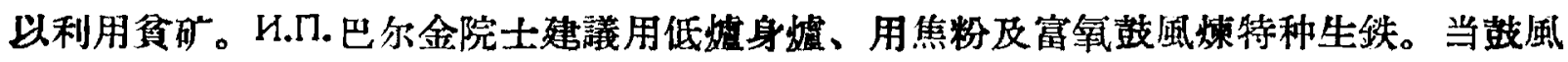
含氧达 $30 \%$ 时，惯頂煤气的發热量达 1,500 卡/立方米左右，而経游价值則取决于氧的 价銭。

为了强化过程, 必須保証应有的嘘料准备工作一一选矿、混匀、燒結; 尤其是因为

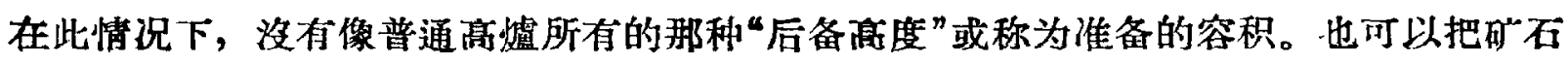
与熔剂和知料混合，一同团矿，这样能够大大加速过程，利减少燃料消耗。

从低嘘身媎煤鉄的現有經驗还不足以制断它是否适于广泛应用。在个別国家里，值

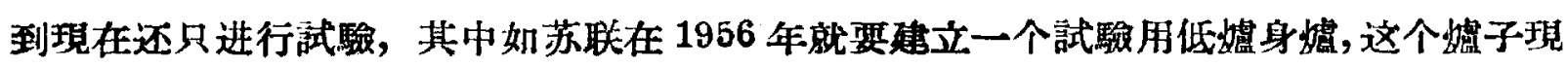
在正在設計。

\section{四煤釗}

关于銅在国释济.上的价值是無需証明的了，从鋼的生产量以及鉄的生产量都可以 12 月号 科学道报 
刵断国家的实力和治金科学的水本如何。合金鋼的制造問題将具有特別重大仢意义，对 合金鋼的裂求是特別大的。指出下列一点就足以說明，在装备原子核反应堆及原子能發 电部时就雾要高合金鎆。

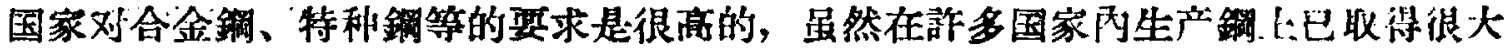

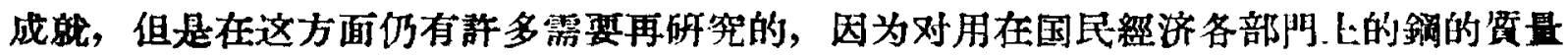
不断产生着新的要求。

精密仪器制造的發展是对原子核动力技术的順利器展不可少的，而精密仪器制造的

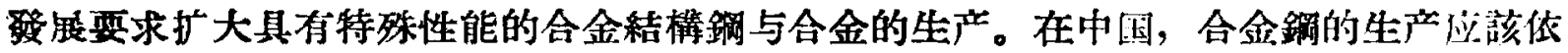
靠删些中国所不缺之的合金元素来發展。

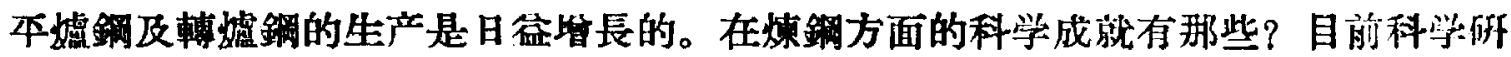
究工作的發展方向又如何呢?

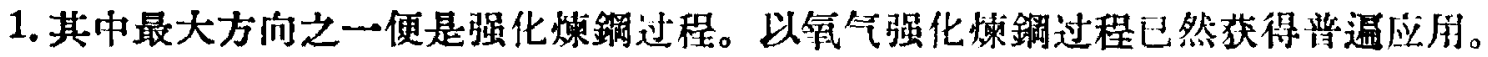

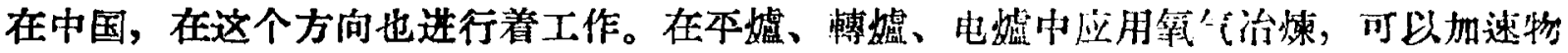
理化学过程的进行，因而就可以大大提高这些嘘子的生产率。

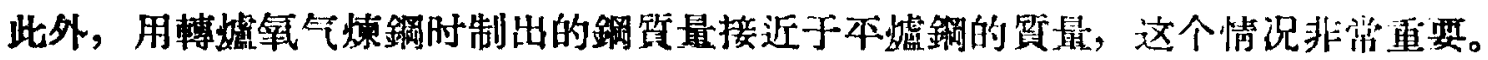

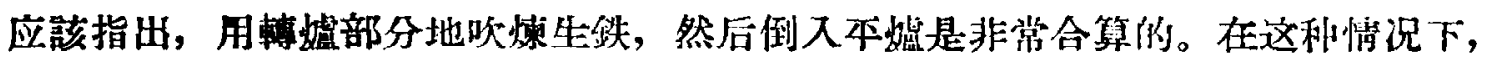

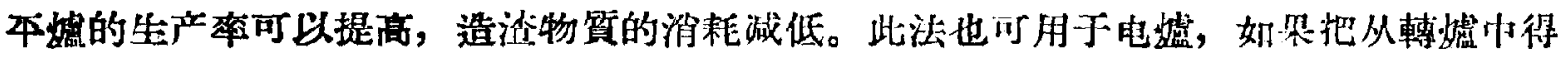

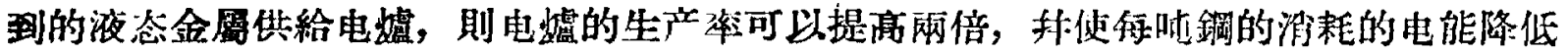
一纵。圆 5 为最合理的通入氧气的方法。

在苏联，平媤的容积不断地在㘿大，按 照在 300 吨区上不可可傾式本觜中所煉出金 禹的比雷来謨，苏联占世界第一位。例奶， 容量 350 吨以上的復中所得金屬数最，在苏 联为 $25.8 \%$ ，而在美国仅 $2.3 \%$ 。本朗的吨 位还在不断地提。已实現 500 吨本烧的建

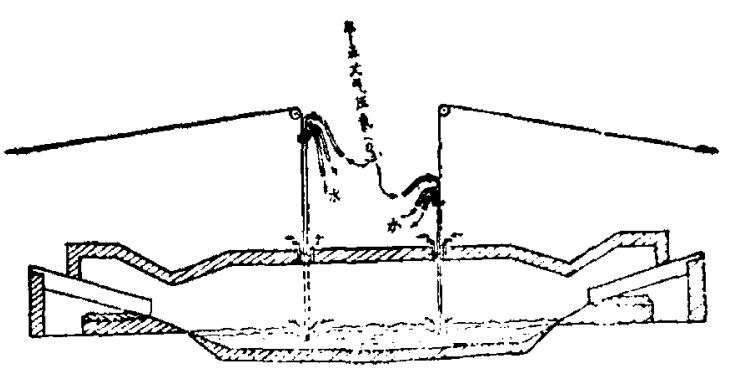

闵 5

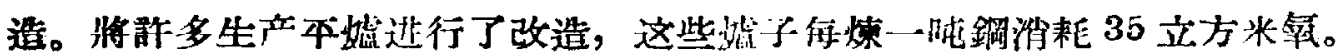

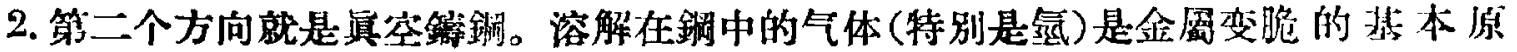

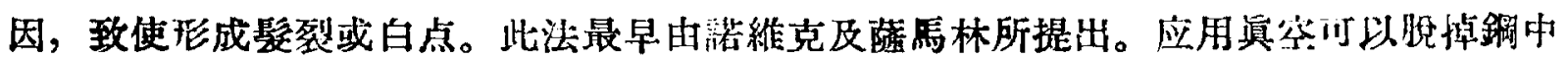

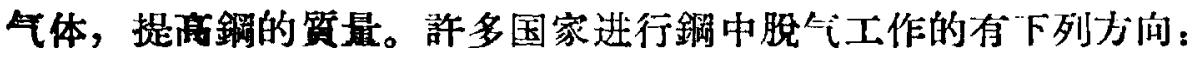

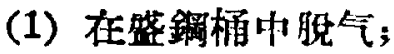

(2) 在出堸过程中脱气;

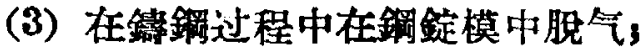

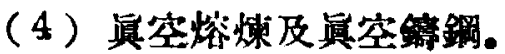

用这些方法提奥鋼的睤量具有很大的国民紅济意义。現在国外对这个問題非常重

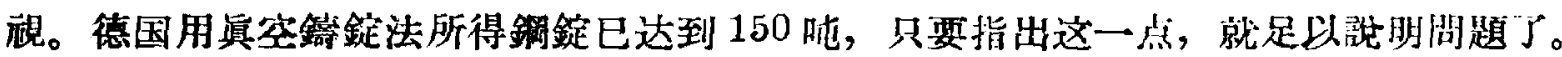

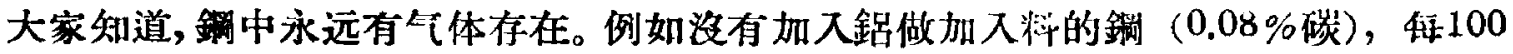
克就含 42 立方倡米气体，其中含经达 23 立方厘米。

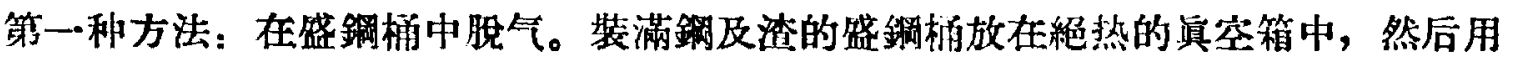




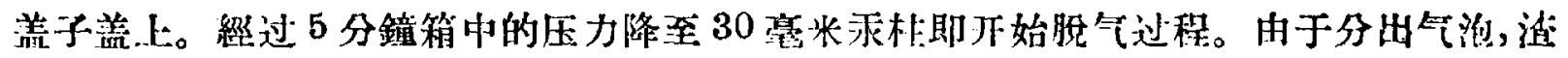

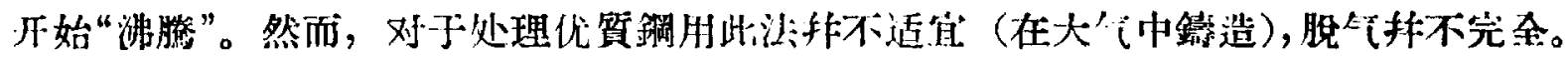

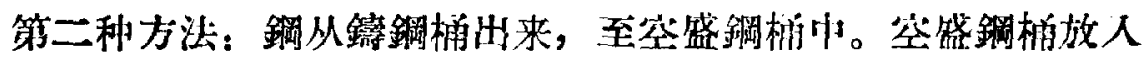

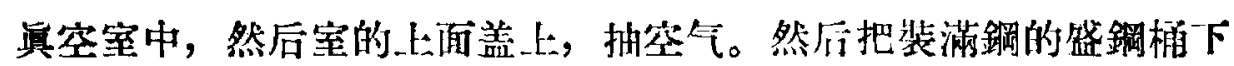

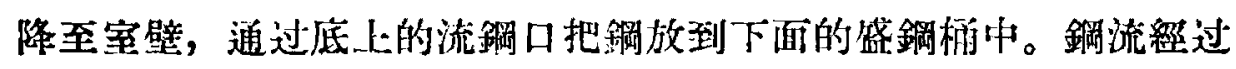

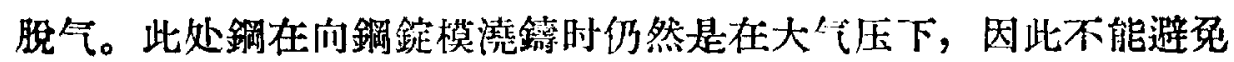
三次吸收匍，然而，仍可得到很好的結果。

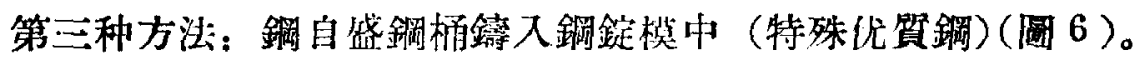

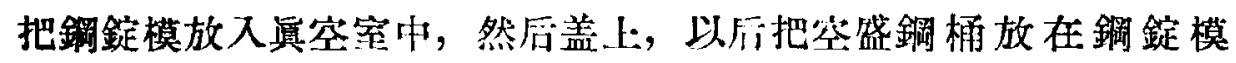
上，然后自第二个盛鋼桶中把鋼注入空的盛鋼桶，自空的盛鎆桶注 入鋼鉈模中。

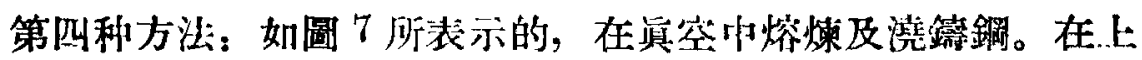

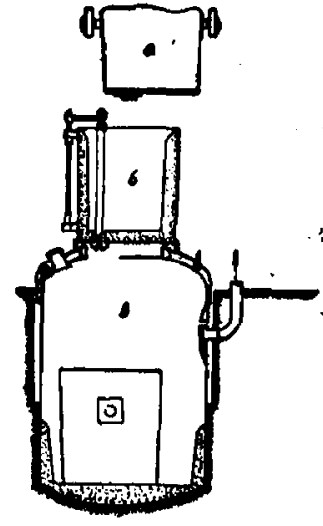

国 6 面的a 宝中吊着一个裝滿的容器, 这个察朋一个開門与 6 室相通, 6 室中放一个容积

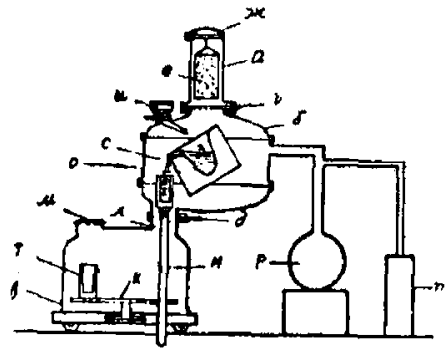

四 7 450 公厅的感应电嘴，下面有一个室，其中放着鋼鍁模及联

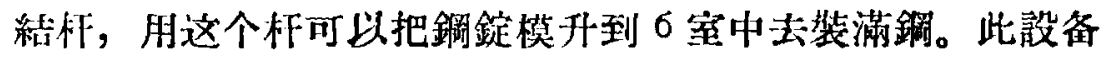

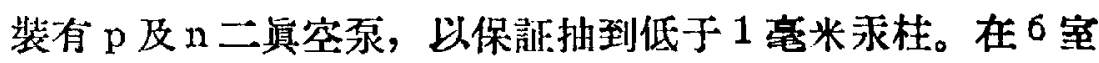
的侧端放一个料斗 u以便供給补冭的料。它是用网个䦎閂

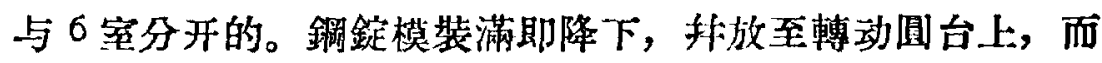

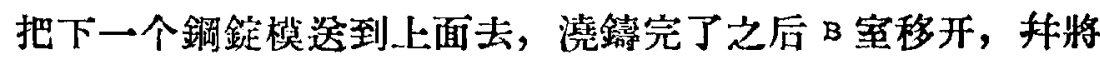
带有鉦的模子拿出，依此得环。

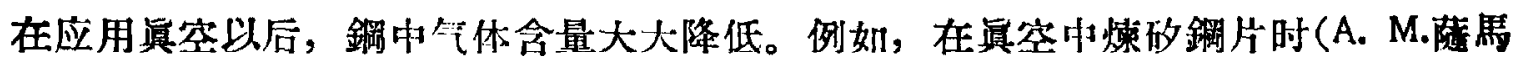
林的資料), 气体含量大大降低, 由下溒即可看出:

\begin{tabular}{|c|c|c|}
\hline & 0 & $\mathrm{H}$ \\
\hline 普通爐子烜出的啁 & $0.0145-0.0195$ & $0.0002-0.0004$ \\
\hline 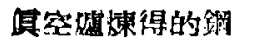 & $0.001 \mathrm{~J}-0.0026$ & 0.00005 \\
\hline
\end{tabular}

在具空㩇中剩余气压为 $1-10$ 毫米承杜。

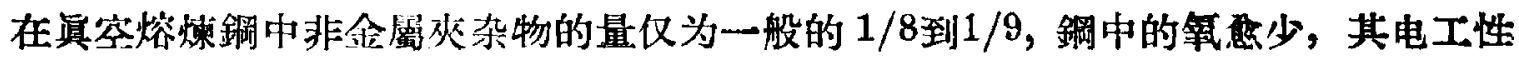

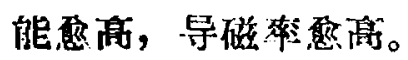

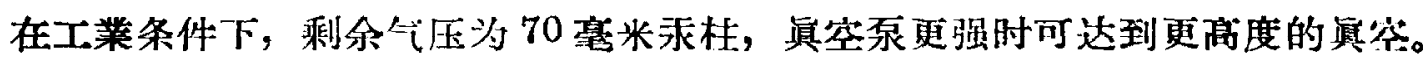

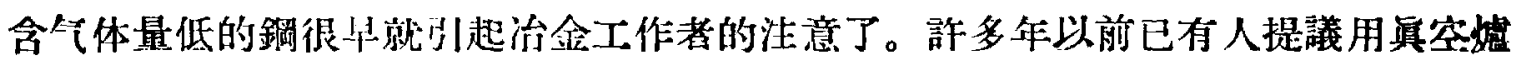

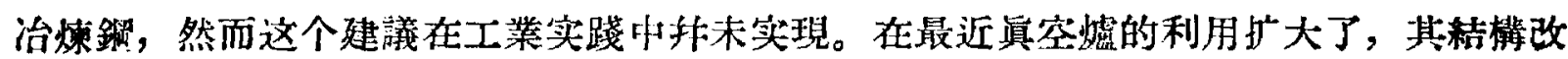
进了，容积增大了。琴代技术手段已使我們能够永用一些方法去获得質最优良的鋼了。

在工業規模下制造特和龬及制造合金具有重大意义。

在中国科学院的長远規划中可以考虑在工厂及研究所的实驗宝中进行許多研究工 倠，以侹制定更完善的鋼及合金脱气方法，以瑅高鋼的質量，井使非金風夾杂物的含量 降至章通的 $1 / 8$ 到 $1 / 10$ 。 


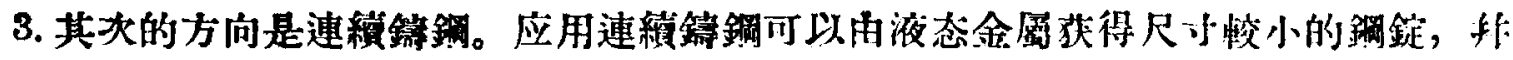
大大樎短生产过程，因为不要那些策重的操作了。首先，不需要初札机了，忋此，减少

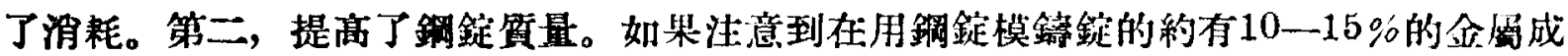

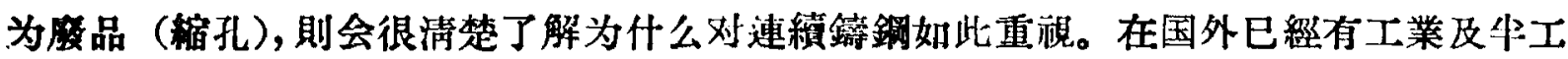

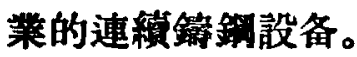

最主要的設备零件是一个銅的無底的全模，具有很重的厚达 150 毫米的堡（固 8 ）。 壁內部有螺旋形的瑇，为通冷却水用 (600升/分)。伤模是可在正㨁方向往复运动的。弁 可以与鏠一道下20毫米, 然后以三倍的速度回来。

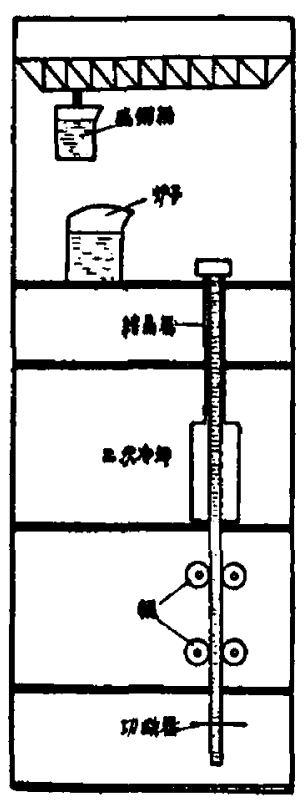

8

这样可以保証鎮表面純凈，可預防金屬粘着到壁上的订能性。 在上部 90 毫米長度上㠜固的壳有 3-12毫米，锭模的滈度为 500 豪 米。只有在 50-100 毫米的地段上冾却作用最大，下部热最傳出速 度、凝固速度均下降。

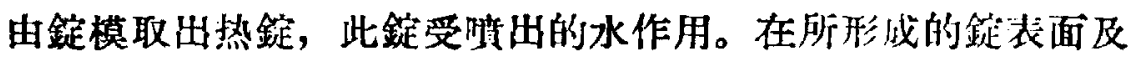

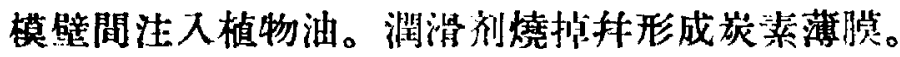

在金模及拔鉈的輥子之間有中間的輥子，它可帮助鋕成形。鋳 造速度为 1,900 豪米/分 (24吨/时), 也叮能更高。很清楚, 各种設 备有不同的結構。此处所誉为一牛工慗的設备結搆及操作。

連續鋳銅的缺点：冷隔及山㨨。在拢錠速度大时，已凝固的外 壳断裂。

連續錪造的优点：应当指出，在这科情况下 $\mathrm{S} 、 \mathrm{P}$ 的帶狀 偏 很弱。拢定速度为 0.6 - 0.8 米/分。銀造速度为 0.4 吨/分（断面 150 $\times 470-500$ )。

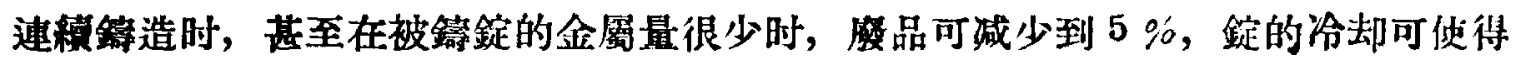
晶粒較細，锭的中心部分疏松度小。

随着中国冾金業的發展，应用連續鎬鋼的問題便有了特別的意义。在这方面应該进 行一些工作以便改进操作技术及研究更完盖的工艺过程与工業設备。

4. 本蛙自动化: 最近本嘘操作自动控制問題获得了重大意义。应用自动控制系統来

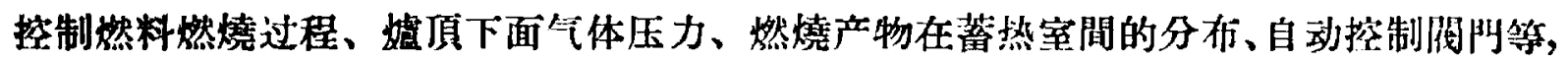
都大大改进㠊子操作及提高生产率。

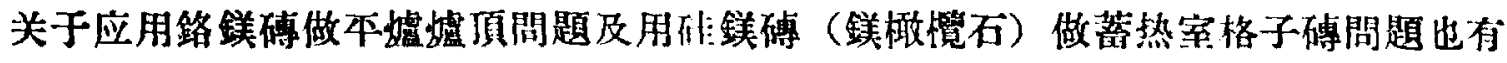
很大意义。应用这些耐火材料，配合以自动化便可以大大提高旗子生产案，抹叮确定便 合理的热制度。

5. 莱鋼过程物理化学原理。

在嫃鋼过程特殊的物理化学研塋方面，在許多国家中都进行着大最工作。其小还 有:

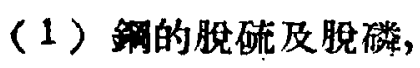

(2) 鋼鉈結棈的呼究,

（3）鋼中非金漹炎杂物， 
(4) 金屬脱碳动力学,

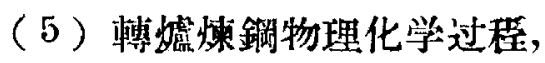

(6) 渣系的研究,

（7）晶体形成机構及鋼結晶过程动力学,

（8）蓄热器中空气預热动力学,

（9）平嘘中热流分有与各因素关系的研究（燃料的消耗、过量空气等）,

(10) 强化平嘼操作的各种条件的研究。

应該特別指出，应用放射性同位素研究冶金过程，例如，測定气体运动速度，研究

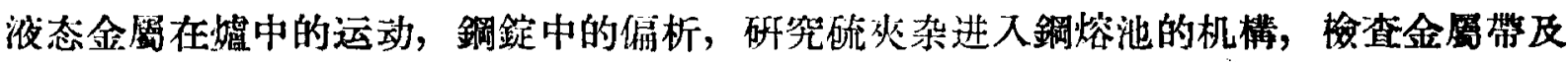
板的生产，鉄的氧化动力学，渣及金屬相間鉄的分布及交換，耐火堵被对銅中夾杂的影 响，扩散問題，在涾与金屬相之間各种金盗的分布等許多問題。

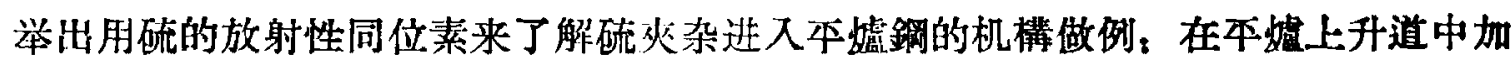
入含放射性硫的硫酸溶液, 在治煉过程中取进入嘘中的分样及自嘘中出来的气样, 投取 渣样及金屬样。当䣓加入硫后極短时間內，渣中硫含量及金屬中硫含最比例很块就等于

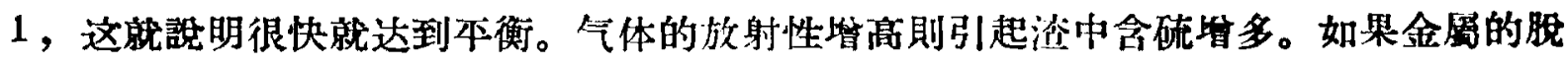

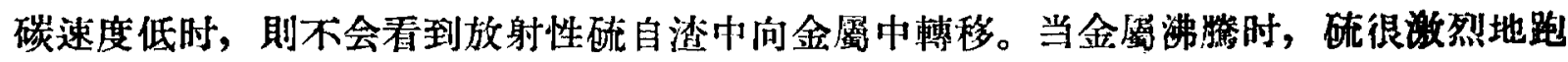

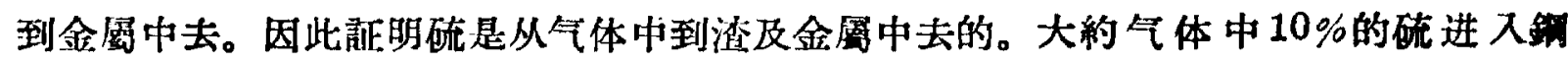
中。

我想，从 1957 年开始，或者更早些，在中国定將开展利用放射性同位素研究冶金过 程的工作了。

〔王景蝹挥】

\section{〔上接 73 頁}

义 (实际上不希然得到相应的报答)，供給大量有 历史价值的旧标本，\#曃慨地把分十多年积照的 經驗介粉出来。

抗日战爭結束后外久，他谓給我所每一个研

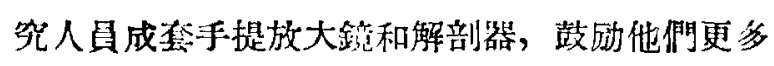
更好地工作以弥补过去提失的岁月。

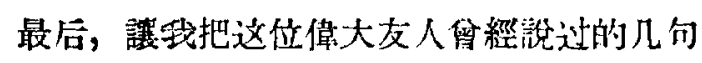

話作为本文的結語吧。

“植物是不受国界約束的, 在国际的不㔹調和

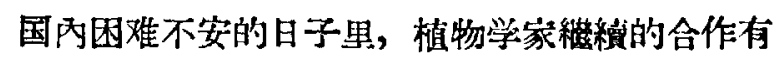
可能很好地影响其他科学团体趋问国际合作。在 政治和桱济的变化下，这一种几抴紀前已經建立 起来的、而且还在落是着的互助精神，是植物科 学对国际友部的重大貢献之一。”

\section{更 正}

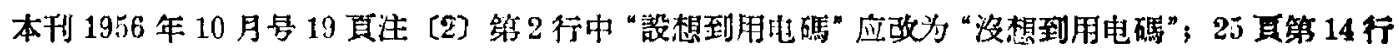
“在 2500以上”应改为在 2500 以下”; 26 面第 7 行“4избыточность”应改为 “избыточность"; 28 直第 34

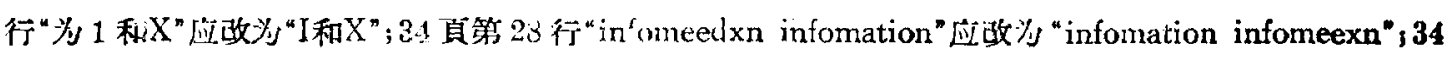
頁第 29 行“热力学單位”应改为“热力学參最”。 